\title{
Molecular differentiation between velogenic isolates and lentogenic LaSota strain of Newcastle disease virus
}

Marwa M. Awad, Samah M. Mosad, Ali A. El-Kenawy

Department of Virology, Faculty of Veterinary Medicine, Mansoura University, Mansoura, Egypt

\section{ARTICLE HISTORY}

\section{Received: 21.06 .2020}

Revised: 13.07 .2020

Accepted: 24.08 .2020

Address correspondence to Rehab Marwa M. Awad; Tel. 01006735970, Email:drmeroawad@gmail.com

\section{ABSTRACT}

\begin{abstract}
Objective: Isolation, serological and molecular identification and differentiation between velogenic and lentogenic of Newcastle disease virus (NDV) strains. Design: Descriptive study.

Procedures: In this study, A total of 24 Pooled samples were collected from Dakahlia, Egypt, from 2017 to 2018 .The virus was isolated in 10 days old (ECEs) and serologically identified in third egg passage allantoic fluid by Haemagglutination (HA), Haemagglutination inhibition test (HIT) and agar gel precipitation test (AGPT). Molecular confirmation was done by reverse transcriptase-polymerase chain reaction (RT-PCR). Genetic diversity between velogenic and lentogenic NDV strains was done by RT-PCR amplification of 254bp F gene fragment from velogenic NDVs and sequence analysis of 362 bp NDV F gene fragment.

Results: Out of 24 tested samples, 20 samples were collected from allontoic fluid of $3^{\text {rd }}$ passage positive by HA test, 18 samples by HIT, 16 samples by AGPT and 18 isolates were positive with RT-PCR amplification of $362 \mathrm{bp} F$ gene fragment. LaSota strain gave positive results in HA, HIT, AGPT and RT-PCR amplification of 362bp fragment. Interestingly, 254bp fragment failed to be amplified from LaSota strain. The phylogenic analysis revealed that our isolates were related to Egyptian velogenic genotype VII NDVs. The deduced amino acid sequence of the $F$ protein cleavage site of our isolates was characteristic of velogenic NDVs $\left({ }^{112} R-R-Q-K-R^{\downarrow} F^{117}\right)$ while LaSota strain had characteristic lentogenic NDVs cleavage site $\left({ }^{112} \mathrm{G}-\mathrm{R}-\mathrm{Q}-\mathrm{G}-\mathrm{R}^{\downarrow} \mathrm{L}^{117}\right)$.

Conclusion and clinical relevance: Sequencing and phylogenetic analysis of $362 \mathrm{bp} F$ gene fragment can detect the genotype of NDV. RT-PCR amplification 254bp NDV F gene fragmentsis and deduced amino acid sequence can differentiate between virulent and low virulent NDVs.
\end{abstract}

Keywords: NDV; HA; HIT; AGPT; RT-PCR; F gene; phylogenic analysis.

\section{INTRODUCTION}

Newcastle disease (ND) is a very contagious respiratory infection of wild and domestic birds of different avian species and believed to be one of top economically serious diseases all over the world [1]. The first report of NDV was in Indonesia (Java)and in England (Newcastle-upon-Tyne) in 1926 then the NDV was reported in central Europe then later in various parts of the world [2]. In Egypt, the first report of NDV was in 1931where the virus was reported from Giza governorate [3] then NDV was isolated from Upper Egypt in 1959 [4]. Some isolates of NDV migrating to Egypt showed velogenic NDV marked viscerotropic characters for chicks [5] After that many outbreaks of NDV were reported in commercial chicken flocks causing severe economic losses in poultry industry [6].

ND caused by Avian orthoavulavirus1 that related to order Mononegavirales, family Paramyxovidae, subfamily Avulavirinae and genus Orthoavulavirus [7].NDV was classified as; class I in which the NDV strains are all grouped into a single genotype and three subgenotypes and Class II in which the NDV strains are classified into 18 genotypes from genotype I to genotype XVIII, all genotypes are subdivided into various subgenotypes [8]. NDV is apleomorphic virus as appeared under Electron Microscope (EM) in two forms, rounded form (100-500 $\mathrm{nm}$ in diameter) and filamentous forms (100nm across with variable length). The NDV envelope is covered with glycoprotein spikes of about $8 \mathrm{~nm}$ length, the helical nucleocapsid appears as "herring bone" of about 18 $\mathrm{nm}$ width [9].

The genome of NDV isabout $15 \mathrm{~kb}$ nonsegmentednegative single stranded RNA genome. The NDV genome carries six genes, each gene expresses one protein as following; hemagglutinin-neuraminidaseprotein, fusion protein, matrix protein,phosphoprotin, nucleoproteinand RNApolymerase protein [10]. Even the severity ND varies according to the type of host and NDV strain, low virulent NDV strains can causeserious respiratory disease inpoor environmental conditionsor when they triggered with other infectiuos organisms [11].

NDV can infect humans causing self limiting conjunctivitis [12]. NDV is transmitted through direct and indirect contact with diseased or carrier birds [13].Clinical signs of ND seen in infected chickens appear in different forms: asymptomatic form, lentogenic or respiratory form, 
mesogenic form andvelogenic form (viscerotropic and/or neurotropic) [14].

Postmorteum changes of ND are dehydratedcongested muscles, dehydrated carcass, periventricular glandstipshemorrhages, congestedliver, enlarged mottled spleen, severe necrosis and ulceration on mucosal surface of Peyer's patches,greenish intestinal contents, and catarrhal tracheitis with hemorrhagic mucosa [15]. NDV is usually detected by serological tests including HA, HIT and AGPT [16]. RT-PCR is usually used for amplification of a specific portion of $\mathrm{F}$ gene including the FO cleavage site, phylogenic analysis of the resulting PCR product $F$ gene nucleotide sequence always used in determining the virulence of NDV. The proteolytic cleavage site of ${ }^{112} R-R-Q-K-R^{\downarrow} F^{117}$ is characteristic for velogenic NDV in class II, genotype VII NDV isand ${ }^{112}$ G-R-Q$G-R^{\downarrow} L^{117}$ is characteristic for lentogenic NDV in class II, genotype II NDV [17].

Although massive vaccination against Newcastle disease virus is used in Egypt, the outbreaks are still causing great economic losses. High genetic evolution of NDV hinders controlling of the disease, so identification and sequence analysis should be continuously done for evaluating the running strains with the other known and vaccinal strains. This study aimed to isolate velogenic NDVfrom suspected chickens, serological identification of isolated virus and molecular differentiation between velogenic isolates and lentogenic LaSota strain of Newcastle disease virus.

\section{MATERIALS AND METHODS}

\subsection{Samples collection}

A total of 120 clinical pooled organ samples (larynx, trachea, lung, proventriculus, spleen and brain) were collected from diseased chickens suspected to be infected with velogenicNDV (vaccinated 8 layers and 16 broiler). These samples were collected from 24 different farms in Dakahlia governorate from 2017 to 2018 and each five samples from the same farm were pooled together to get 24 pooled samples. Three samples were collected from healthy chickens, confirmed to be free from NDV by RT-PCR, pooled together and used as negative control sample.

\subsection{Preparation of collected samples}

The collected clinical samples were collected in isotonic PBS containing antibiotics, homogenized in sterile mortar, centrifuged at $2000 \mathrm{rpm} / 10 \mathrm{~min}$. The supernatants were collected then stored at $-20^{\circ} \mathrm{C}$ until use in trials of virus isolation [11].

\subsection{Standard NDV}

LaSota vaccine (Boehringer Ingelheim, Germany) was used as standard NDV. It is freeze dried modified live virus vaccine prepared from LaSota strain of NDV in SPF chicken embryos, each vial contains $10^{3}$ EID $_{50}$. It was used for hyperimmune serum preparation against NDV and as acontrolpositive strain in HA, HIT, AGPT and RT-PCR. It was also used as alentogenic strain in molecular differentiation between velogenic and lentogenic NDV strains.

\subsection{Virus isolation}

Ten days old ECEs were inoculated via the allantoic cavity with $0.2 \mathrm{ml}$ of supernatant fluid from each samples (5 ECEs/ sample), then incubated for 5 days at $37^{\circ} \mathrm{C}$. Three successive passages were performed; embryos died in the first 24 hours post inoculation (PI) were excluded. Embryos died after 24 hours till 5 days PI were examined for viral lesions. Survived embryos after 5 days were chilled for 24 hours at $4^{\circ} \mathrm{C}$ then the allantoic fluid was collected from chilled and dead ECEs and used in the next egg passage. The allantoic fluid from third egg passage was collected and stored at $-20^{\circ} \mathrm{C}$ until use in serological identification of the virus with $\mathrm{HA}, \mathrm{HIT}$, AGPT and molecular confirmation of the virus with RT-PCR [18].

\subsection{Chicken red blood cells (RBCS)}

Blood sample was collected from brachial vein of NDV free chicken (confirmed by RT-PCR) with $4 \%$ sodium citrate as anticoagulant then centrifuged at $3000 \mathrm{rpm} / 10 \mathrm{~min}$. The packed chicken RBCs was collected and washed 3 times with PBS then diluted to $1 \%$ concentration in PBS [19].

\subsection{Hyperimmune serum (HIS)}

Five white New Zealand rabbits were used; four of them were inoculated intramuscular with $1 \mathrm{ml}$ standard NDV mixed with $1 \mathrm{ml}$ Incomplete Freund's Adjuvant for 5 successive times with one week interval. The fifth rabbit was kept as negative control as it was inoculated with $1 \mathrm{ml}$ PBS mixed with $1 \mathrm{ml}$ Incomplete Freund's Adjuvant by the same manner. To observe the antibody titer against standard NDV in inoculated rabbits, periodical serum samples were collected and tested for anti-NDV antibodies by HIT. The rabbits were bled 2 weeks after the last inoculation, their serum was collected, heat inactivated at $56^{\circ} \mathrm{C} / 30 \mathrm{~min}$ then stored at $-20^{\circ} \mathrm{C}$ till use in HIT and AGPT [20].

\subsection{Serological identification of isolated virus by HA, HIT and AGPT}

Haemagglutination was conducted for the detection of haemagglutinating viruses for the third egg passage allantoic fluid of the 24 inoculated samples, control positive (LaSota strain) and control negative samples. The allantoic fluid from each sample, control positive and control negative samples were diluted (2fold serial dilution), then $25 \mu$ of $1 \%$ washed chicken RBCs was distributed to each well, the solution was mixed by flipping the plate gently then the RBCs were leaved to settle down at room temperaturefor around 40 minutes. When RBCs in negative control wells were settled down forming a distinct button, the end points were calculated as the highest dilution of NDV causing complete haemagglutination; this represents 1 haemagglutinating unit (HAU). The virus concentration containing $4 \mathrm{HAU}$ was prepared from each HA positive isolate (allantoic fluid of third egg passage) to be used in HIT [10]. 
HIT, $\beta$ procedure (constant virus with diluted serum) was conducted for detection of NDV in HA positive allantoic fluid of the third egg passage. Twofold serial dilution of heat inactivated HIS was prepared then $25 \mu$ l of constant virus concentration (4HAU) from allantoic fluid of third egg passage was added to each serum dilution. Control positive (LaSota strain) and control negative samples were included. Plates were then incubated for 30 minutes at $37^{\circ} \mathrm{C}$ then $1 \%$ washed chicken RBCs $(25 \mu \mathrm{l})$ was distributed into each well, mixed gently and the RBCs were leaved to settle down at room temperature or around 40 minutes. When the RBCs in the negative control wells were settled down forming a clear button, the $\mathrm{HI}$ titer was detected as the lowest serum concentration causing complete inhibition of the haemagglutination [21].

AGPT was used for NDV identification in the allantoic fluid of the third egg passagefrom the 24 inoculated samples, control positive (LaSota strain) and control negative samples. The agarose gel was prepared as $1 \%$ concentration in distilled water. A central well and 6 peripheral wells were punched in the agar, the central well was filled with HIS while the surrounding wells were filled with allantoic fluid of third passage from the 24 isolates, control positive and control negative samples. Plates were incubated at $37^{\circ} \mathrm{C}$ with $70 \%$ humidity and examined 24hours later up to 5 days for observation of precipitation lines [22].

\subsection{Molecular confirmation of the isolated virus}

Viral RNA was extracted from allantoic fluid of third passage from the 24 isolates, control positive (LaSota strain) and control negative samples using the QIAamp MinElutVirus Spin Kit (Qiagene, GmbH, Germany- Lot no. 157014352) as indicated by the manufacturer's instructions.

RT-PCR was used for detection of velogenic and lentogenic strains of NDV by amplification (362 bp) fragment of $F$ gene and differentiation between velogenic and lentogenic strains of NDV by amplification of (254 bp)fragment of NDV F gene from velogenic NDV strains only using the primer sets that previously reported [5] Table(2).The primers were synthesized in Germany by Metabion International AG.RT-PCR was done using TOP script ${ }^{\mathrm{TM}}$ One-Step RT-PCR kit (enzymotics, Korea) according to manufacturer's instructions. The reaction mixture consisted of, $5 \mu$ l One- step RT PCR mix, $2 \mu$ l extracted RNA, $1 \mu$ l (10 pmol) of forward and reverse primers for each NDV $F$ gene fragment as following; $A+B$ primers for amplification of 362 bp NDV F gene fragment and $A+C$ primers for amplification of $254 \mathrm{bp}$ NDV $\mathrm{F}$ gene fragment and nuclease free water was finally added up to $20 \mu \mathrm{l}$. The thermal cycler (T3 Biometra, Germany) was adjusted into, one reverse transcription cycle at $50^{\circ} \mathrm{C}$ for $30 \mathrm{~min}$ followed by single initial denaturation cycle for $10 \mathrm{~min}$ at $95^{\circ} \mathrm{C}$ then 40 cycles of three steps; denaturation $\left(95^{\circ} \mathrm{C} / 30 \mathrm{sec}\right)$, primer annealing for $30 \mathrm{sec}$ at $52^{\circ} \mathrm{C}$ for $\mathrm{A}+\mathrm{B}$ primer pair and $45^{\circ} \mathrm{C}$ for $\mathrm{A}+\mathrm{C}$ primer pair and extension for $1 \mathrm{~min}$ at $72^{\circ} \mathrm{C}$ with final extension cycle at $72^{\circ} \mathrm{C}$ for $10 \mathrm{~min}$ [5].Then the PCR products were separated with
100 bp DNA ladder (Jena Bioscience, Germany) in agarose gel (1.5\%) prepared with $0.5 X$ Tris-Borate EDTA buffer. The obtained DNA bands were visualized with UV trans illuminator [23].

Amplified 362 bp DNA bands of NDV F gene were cut off then extracted from the gel with QIAquick PCR gel purification kit (Qiagen Inc., Valencia, USA) in accordance with kit's guidance. Purified PCR products were then brought to Korea (MACROGEN laboratory) for two directional DNA sequencing using the same RT-PCR primer set. The gained nucleotide sequences were deposited in the GenBank (http://www.ncbi.nlm.nih.gov/Genbank) under the following accession numbers; MN537832 for Mans 1 isolate, MN537833 for Mans 2 isolate, MN537834 for Mans 3 isolate and MN537835 for LaSota strain.

Neighbor-joining distance tree was constructed with the obtained sequences together with other sequences from Genbank Figure 4. according to the kimura-2-parameter model with 1000 Bootstrap repeats test in MEGA X software [24]. MEGA X software also used to calculate the distance between studied isolates, LaSota strain sequenced in this study and other NDV strains from GenBank Bioedit software package [25] was also used for clustal-W alignment of deduced amino acid sequences of our isolates, LaSota strain sequence in this study, Egyptian velogenic NDV isolates in class II, genotype VII of NDV and lentogenic NDVs in class II, genotype II of NDV(LaSota strains) from NCBI with Dakahlia28 strain as a reference strain.

\section{RESULTS}

One hundred and twenty clinical samples were collected from chickens suspected to be infected with velogenic NDV,each five samples were pooled together to get 24 pooled samples. These samples were collected from 24 different farms ( 16 broiler with age ranging from 35-39 days with mortality rate ranging from $70-95 \%$ and 8 layer with age ranging from 130-150 day with mortality rate ranging from 3$5 \%$ ) in Dakahlia governorate, Egypt from (2017 to 2018) Table 1. Diseased chickens were suffering from respiratory signs of watery discharge from nostrils labored breathing, gasping, coughing, sneezing and facial swelling together with digestive signs of greenish diarrhea. Also nervous signs were observed in some birds including, paralysis of wings and twisted neck Figure $1 \mathrm{~A}$. The postmortem findings were pin point hemorrhages at the tip of proventricular glands and enlargement of spleen, hemorrhagic ulcers in intestinal wall and Payer's batches, petechial hemorrhage in colon and greenish intestinal contents Figure 1B. Hemorrhagic lungs, tracheitis and catarrhal exudates were also observed. Mortality rates were ranging from $70-95 \%$ in broiler chickens and $3-5 \%$ in layers.

Out of 24 tested samples, 20 samples (83.3\%) and control positive sample showing embryo mortality(1-5 days post inoculation), embryos that survived for 24 hours till 5 days showed hemorrhage in the whole body with edema in the 
head region, abnormal feathering, dwarfism and congestion Figure $1 \mathrm{C}$. While the other 4 samples (16.7\%) and control negative sample showed no changes in inoculated eggs and inoculated embryos survived up to 5 days Table 3.
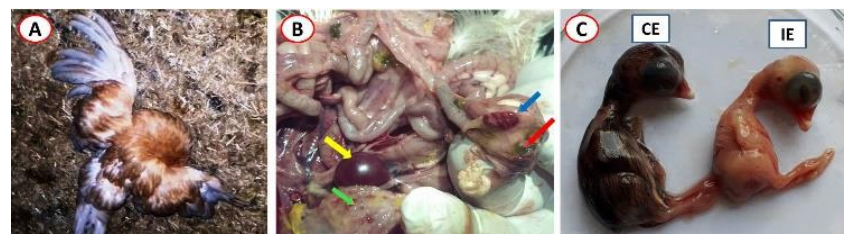

Figure 1. Clinical signs, postmortem changes of diseased chickens and lesions of virus isolation in ECE. A) Chicken showing nervous manifestation of twisted neck and paralysis of wings. B) Hemorrhagic ulcers in Payer's batches (blue arrow), enlarged spleen (Yellow arrow), pin point hemorrhages at the tip of proventricular glands (Green arrow) and greenish diarrhea (red arrow). C)lesions of virus isolation in ECE (CE) Uninfected control chicken embryo (IE) infected chicken embryo, 5 days post inoculation showing congestion, dwarfing and abnormal feathering.
A

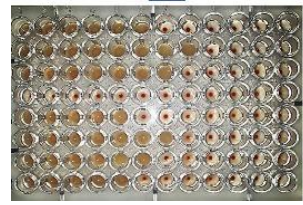

B

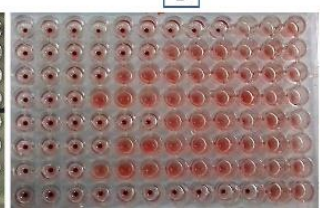

C

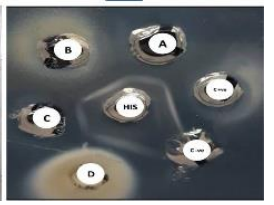

Figure 2. Serological identification of isolated virus in the allantoic fluid of the third egg passage. A) HA; positive result appears as lattice shape and negative result appears as button shape. B) HIT; positive result appears as button shape and negative result appears as lattice shape.C) AGPT, positive samples produce precipitation line, HIS=Hyperimmune serum, $\mathrm{C}+\mathrm{ve}=\mathrm{control}$ positive, $C$-ve=control negative, $A, B, C, D$ tested isolates.

\section{A}

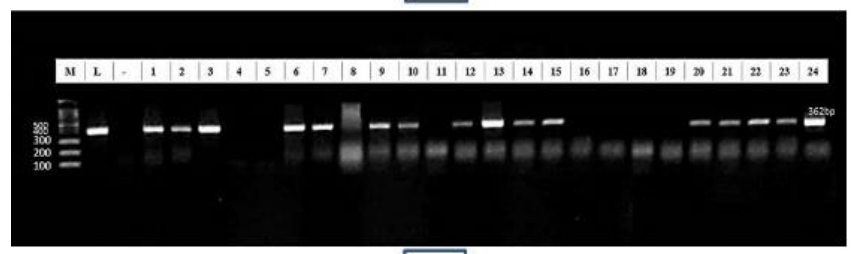

B

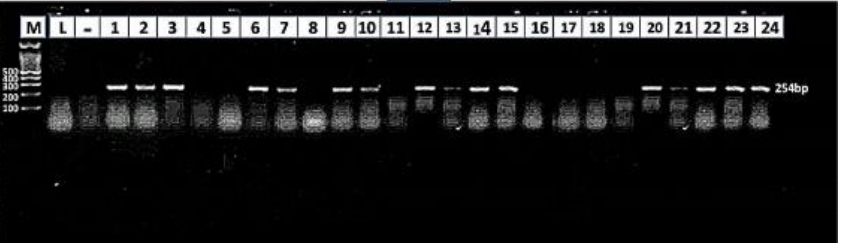

Figure 3. Gel electrophoresis of PCR products of 24 tested samples for F gene at (365 pb and $254 \mathrm{pb}), \mathrm{M}=$ marker, L= LaSota strain, -= control negative, 124 = tested isolates. A) PCR products of 362 bp NDV F gene fragment and B) PCR products of $254 \mathrm{bp}$ NDV F gene.

Out of 24 tested isolates, 20 isolates(83.3\%) and control positive sample were positive with virus titer ranging from $2^{5}$ to $2^{11}$ while the other four samples $(16.7 \%)$ and control negative sample were negative Figures 2A, Table 3 .

HIT was used for identification of the isolated virus (4HAU)in20 HA positive isolates (allantoic fluid of third egg passage) using HIS prepared against standard NDV. Out of 20 tested isolates, 18 isolates and control positive sample were positive with antibody titer ranging from $2^{3}$ to $2^{10}$ while the other 2 isolates were negative (Figure2B), (Table, 3).
The allantoic fluid collected from 24 tested isolates (third egg passage) was further identified by AGPT. The positive result appears as clear line of precipitin. Out of 24 tested isolates, 16 isolates (66.7\%) and control positive sample were positive while control negative sample and the other 8 samples (33.3\%) were negative showing no line of precipitin(Figure $2 \mathrm{C}$ ), (Table, 3 ).

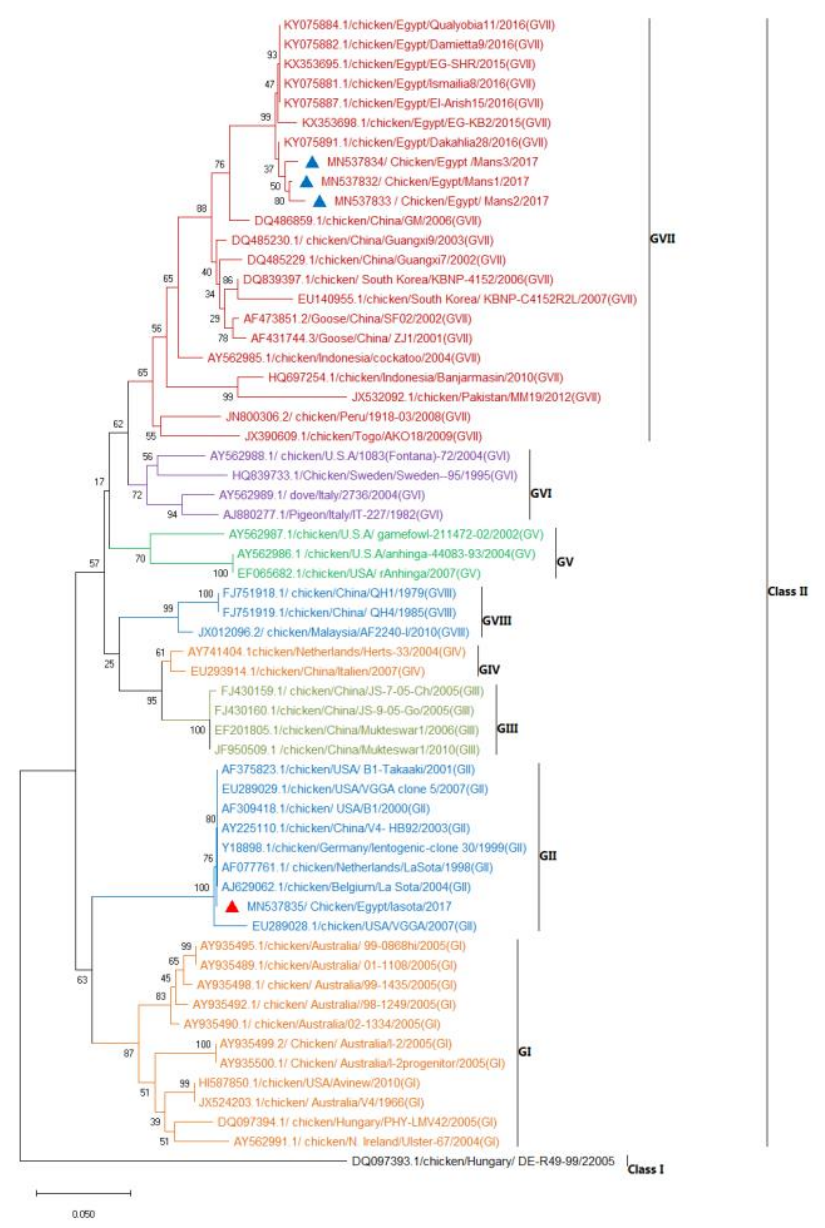

Figure 4. The phylogenetic tree of the nucleotides sequences analyzed by MEGA X software; showing that the three studied isolates (blue triangles) were more closely related to velogenic class II, genotype VII NDVs as they were clustered in the same clade. While standard NDV (LaSota) (red triangle)(Egyptian Lasota) was more closely related to lentogenic class II, genotype II NDV as they were clustered in the same clade.

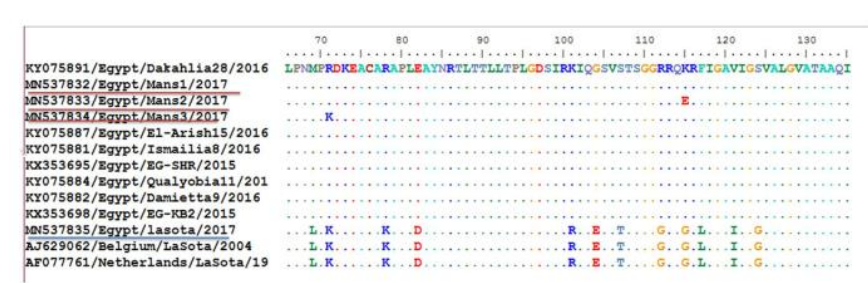

Figure 5. Amino acid sequences alignment showing amino acid substitution in one site in Mans2 isolate, amino acid substitution in one site in Mans3 isolate and amino acid substitution in 12 sites in lentogenic LaSotastrains in genotype II of NDV when compared with velogenic strains in genotype VII.

Out of 24 tested isolates using A+B primer pair,18 isolate (75\%) and control positive sample (LaSota strain)expressed the positive expected band at 362 bp while other 6 isolates $(25 \%)$ and control negative sample were negative 
show no bands at $362 \mathrm{bp}$. Out of 24 tested isolates using $A+C$ primer pair,18 isolate (75\%) were positive and gave the expected band at $254 \mathrm{bp}$ while other 6 isolates $(25 \%)$, control positive lentogenic strain of NDV (LaSota strain) and control negative sample were negative show no bands at $254 \mathrm{bp}$ (Table, 3).

Table 1. Detailed description of the oligonucleotide primers used in RT-PCR.

\begin{tabular}{|c|c|c|c|c|c|}
\hline $\begin{array}{l}\text { Primer } \\
\text { Name }\end{array}$ & Sequence $\left(5^{\prime}-3^{\prime}\right)$ & $\begin{array}{l}\text { Target } \\
\text { gene }\end{array}$ & $\begin{array}{l}\text { Expected } \\
\text { Product } \\
\text { Size(bp) }\end{array}$ & $\begin{array}{l}\text { Annealing } \\
\text { Temperature } \\
\text { For } \mathrm{PCR}\left({ }^{\circ} \mathrm{C}\right)\end{array}$ & Reference \\
\hline A & TTGATGGCAGGCCTCTTGC & F-gene & 362 & 52 & \\
\hline
\end{tabular}

Table 2. Comparative of NDV isolation, serological identification using HA, HIT, AGPT and molecular characterization by RT-PCR, ${ }^{*} \mathrm{NA}=$ not applied.

\begin{tabular}{|c|c|c|c|c|c|c|}
\hline \multirow[t]{2}{*}{ Sample } & \multirow[t]{2}{*}{$\begin{array}{l}\text { Result of } \\
\text { Virus } \\
\text { isolation }\end{array}$} & \multicolumn{3}{|c|}{ Serological identification } & \multicolumn{2}{|c|}{$\begin{array}{l}\text { Molecular } \\
\text { characterization by } \\
\text { RT-PCR }\end{array}$} \\
\hline & & HA & HIT & AGPT & $\begin{array}{l}362 b p \\
\text { fragment }\end{array}$ & $\begin{array}{c}254 b p \\
\text { fragment }\end{array}$ \\
\hline 1 & + & $2^{6}$ & $2^{9}$ & + & + & + \\
\hline 2 & + & $2^{8}$ & $2^{6}$ & + & + & + \\
\hline 3 & + & $2^{7}$ & $2^{8}$ & + & + & + \\
\hline 4 & - & - & NA & - & - & - \\
\hline 5 & + & $2^{5}$ & $2^{10}$ & - & + & + \\
\hline 6 & + & $2^{7}$ & $2^{8}$ & + & + & + \\
\hline 7 & + & $2^{6}$ & $2^{9}$ & + & + & + \\
\hline 8 & + & $2^{5}$ & $2^{10}$ & - & + & + \\
\hline 9 & + & $2^{11}$ & $2^{3}$ & + & + & + \\
\hline 10 & + & $2^{10}$ & $2^{4}$ & + & + & + \\
\hline 11 & - & - & NA & - & - & - \\
\hline 12 & + & $2^{6}$ & $2^{9}$ & + & + & + \\
\hline 13 & + & $2^{8}$ & $2^{6}$ & + & + & + \\
\hline 14 & + & $2^{9}$ & $2^{5}$ & + & + & + \\
\hline 15 & + & $2^{10}$ & $2^{4}$ & + & + & + \\
\hline 16 & - & - & NA & - & - & - \\
\hline 17 & + & $2^{7}$ & - & - & - & - \\
\hline 18 & - & - & NA & - & - & - \\
\hline 19 & + & $2^{6}$ & - & - & - & - \\
\hline 20 & + & $2^{6}$ & $2^{9}$ & + & + & + \\
\hline 21 & + & $2^{7}$ & $2^{8}$ & + & + & + \\
\hline 22 & + & $2^{11}$ & $2^{3}$ & + & + & + \\
\hline 23 & + & $2^{7}$ & $2^{8}$ & + & + & + \\
\hline 24 & + & $2^{9}$ & $2^{5}$ & + & + & + \\
\hline Total (24) & 20 (83.3\%) & $20(83.3 \%)$ & $18(75 \%)$ & $16(66.6 \%)$ & $18(75 \%)$ & $18(75 \%)$ \\
\hline$C+v e$ & + & $2^{11}$ & $2^{7}$ & + & + & - \\
\hline C-ve & - & - & NA & - & - & - \\
\hline
\end{tabular}

Amplified DNA bands of NDV F gene fragment (362 bp) were sequenced. The resulting sequences were transmitted to GenBank and analyzed together with reference NDV F gene sequences clarified in Figure 4. Alignment of NDV F gene DNA sequences revealed that the isolates identified in this study are more closely related to Egyptian velogenic strains in class II, genotype VII of NDV with $97.00 \%$ to $99.3 \%$ identity. Our isolates were also closely related to velogenic strains in class II genotype VII of NDV from China, South Korea, Indonesia, Peru and Togo with 95.4 to $83.2 \%$ identities. While standard LaSota NDV was more closely related to lentogenic strains in class II, genotype II of NDV obtained from GenBank with $100 \%$ identity as shown in Figure 4, Table 4.
Deduced amino acid sequences of our isolates, LaSota strain identified in this study, The results revealed that the deduced amino acid sequences of tested isolates were identical to that of other Egyptian velogenic strains of NDV in class II, genotype VII of NDV with exception of amino acid substitution at one site (K115E) in Mans2 isolate and amino acid substitution at one site (R71K) in Mans3 isolate. While LaSota strain identified in this study, LaSota strain from Belgium (AJ629062) and Lasota strain from Netherlands (AF077761) were completely identical to each other with amino acid substitution at 12 sites when they were compared with velogenic strains NDV in class II, genotype VII NDVFigure5. 
Interestingly, the deduced amino acid sequence of the $F$ protein cleavage site of studied isolates was ${ }^{112} \mathrm{R}-\mathrm{R}-\mathrm{Q}-\mathrm{K}-$ $R^{\downarrow} F^{117}$ in mans 1 and mans3 strains and ${ }^{112} R-R-Q-E-R^{\downarrow} F^{117}$ for mans2 strain Figure 5. this aminoacid sequence have multiple basic amino acids which are characteristic of velogenic NDVs while deduced amino acid sequence for LaSota strain identified in this study was ${ }^{112}$ G-R-Q-G-R ${ }^{\downarrow} L^{117}$ which is characteristic of lentogenic NDVs.

Table 3.Identity and diversity \% between tested isolates, standard NDV (LaSota) and other sequences from GenBank.

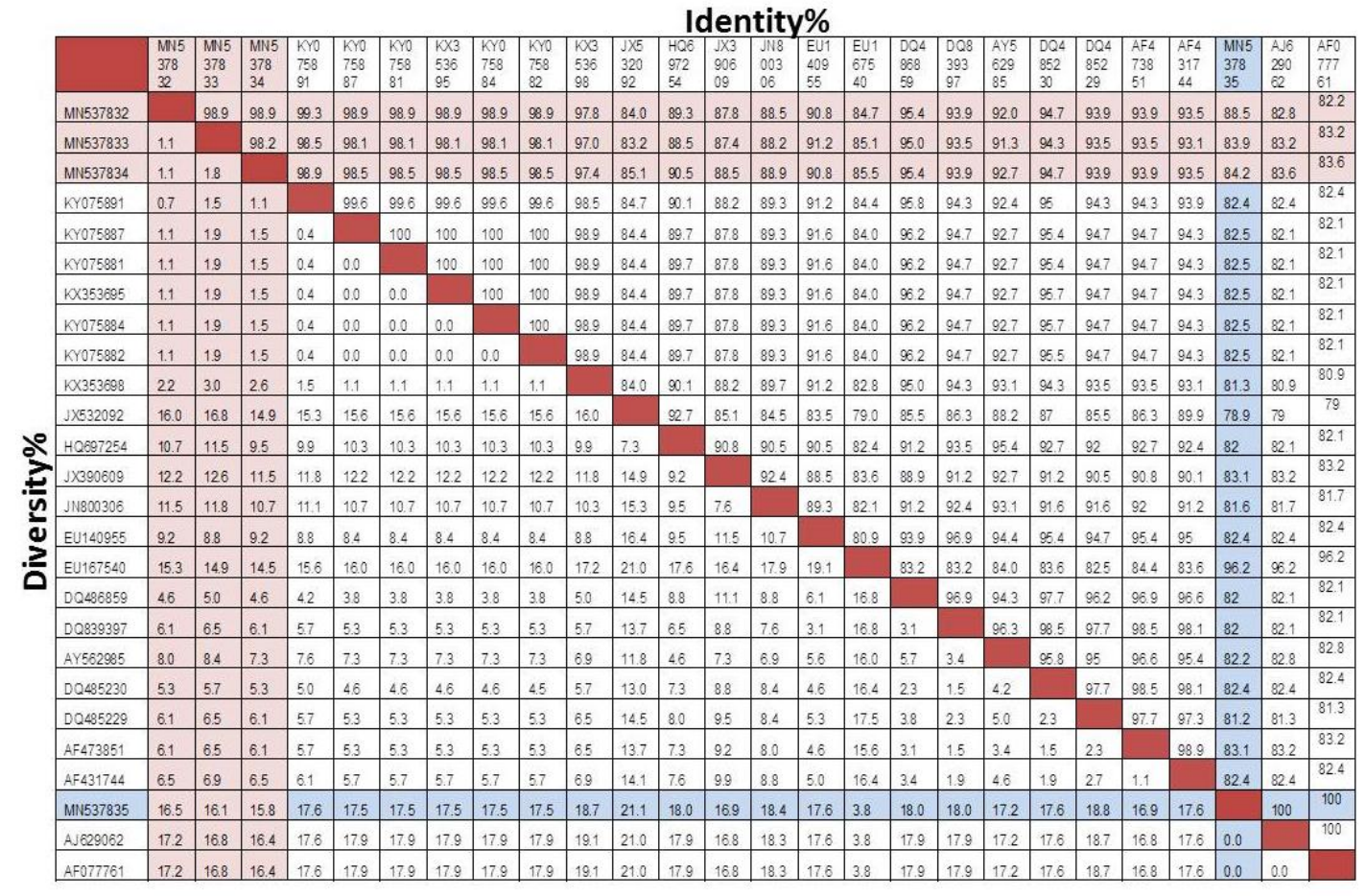

\section{DISCUSSION}

This study was conducted on 24 pooled samples which were collected from 21-29 days old broiler chickens and from 130- 205 days old layer chickens Table 1 . suspected to be infected with velogenic NDV. These ages were in agreement with the results obtained by [25] who observed the disease in 28 day old and 200 day old chickens. Diseased chickens were suffering from respiratory signs, also nervous signs were observed in some birds. These finding were in concurrence with [26] who stated that the clinical signs of NDV in infected birds vary widely depending on virus pathotype which include; nervous signs as twisted neck and paralysis. Respiratory signs of gasping, coughing, sneezing and rales. Digestive signs of greenish diarrhea with soiled vent were also observed. In this study the mortality rates were from 70 to 95\% in broiler chicken, these rates were in accordance with results which recorded that the mortality rates among the examined flocks were 5-85\% and 75\% respectively [27] and [28]. In our study the mortality rates were3-5\% in layer chicken flocks, these finding were in harmony with previous study [29] who found that the average mortality in studied layer flocks infected with velogenic NDV were ranging from 2.89 and $3.50 \%$ and [30] who concluded that the layer flocks infected with virulent NDV have mortality rates ranging from 4.2 to $5.4 \%$.In this study the postmortem findings of affected chickens showed pin point hemorrhages at the tip of proventricular glands, enlargement of spleen, hemorrhagic ulcers in Payer's batches and greenish intestinal contents. These lesions were in agreement with that observed previously [31] who found that the postmortem lesions observed in chickens infected with NDV were; greenish intestinal contents, enlarged mottled spleen, greenish content of proventriculus and gizzard, severe necrosis and ulceration on mucosal surface of cecal tonsils and Payer's batches. The 24 collected samples were prepared then inoculated into allantoic cavity of 10 days old ECEs. Three passages were done, the samples which do not give lesions in inoculated embryos after three blind passages were considered negative in virus isolation. Twenty samples gave characteristic changes in inoculated embryos (83.3\%) as dwarfism, congestion, abnormal feathering and death of embryo while the other four samples (16.7\%) showed no lesions in inoculated embryos. These results were in concurrence with previous results [32] isolated NDV of $80 \%$ from the total samples. The NDV isolated in the allantoic cavity causing death of some inoculated embryos [33] and the subcutaneous tissue of the head is filled with blood and the blood vessels over the body were prominent. While,[34] found that virulent strains of NDV might not kill the inoculated embryos. The isolated virus was identified serologically in collected allantoic fluid of third egg passage 
by HA, HIT and AGPT. The obtained results were confirmed by molecular characterization by RT-PCR amplification of F gene fragment, DNA sequencing of RT-PCR products and phylogenetic analysis of obtained sequences. Allantoic fluid of all isolated samples from third egg passage was tested by haemagglutination with $1 \%$ washed chicken red blood cells for detection of haemagglutinating viruses. Out of 24 tested isolates, 20 isolate $(83.3 \%)$ and control positive sample were positive and the other four samples (16.7\%) and control negative sample were negative. Then $4 \mathrm{HAU}$ was calculated for each HA positive allantoic fluid from the third passage for HIT conduction. These results were in agreement with [35] who described that NDV can cause agglutination of a wide range of RBCs including Chicken RBCs causing its agglutination. HA positive isolates were then tested by HIT to detect the NDV in the allantoic fluid (containing $4 \mathrm{HAU}$ ) which collected from the third egg passage using anti-NDV HIS. Out of $20 \mathrm{HA}$ positive isolates, 18 isolates were positive when tested against anti-NDV HIS in HIT while the other two samples were negative as they may have other $\mathrm{HA}$ virus not NDVas previously described [36] who described that not only NDV can agglutinate chicken red blood cells but also AIV can do it. AGPT was used for detection of NDV in the allantoic fluid from the third passage of 24 tested isolates using HIS prepared against standard NDV. Sixteen samples (66.6\%) and control positive sample were positive as they showing line of precipitin while control negative sample and the other 8 isolates (33.3\%) were negative and showing no line of precipitin. These results were in harmony with [37] who found that $52.9 \%$ of tested samples were positive by AGPT and [38] reviewed that the AGPT can be recommended as a field test for NDV. For differentiation between velogenic and lentogenic NDV strains, RT-PCR was conducted on 24 tested isolates, control positive (LaSota strain) and control negative samples for amplification of $254 \mathrm{bp}$ fragment of $F$ gene which can be amplified from velogenic NDV strains only. Out of 24 tested isolates, 18 samples (75\%) were positive in both RTPCR protocols giving expected bands at $362 \mathrm{bp}$ and $254 \mathrm{bp}$ while the control positive NDV (LaSota strain) gave the expected band at $362 \mathrm{bp}$ and failed to amplify the $254 \mathrm{bp}$ due to point mutation (A380G) at $3^{/}$end of the reverse primer. These results confirmed that the 18 PCR positive isolates identified in this study were velogenic NDVs, these results were in accordance with [39] who detected NDV F gene in collected samples using difference primers. The phylogenetic analysis of these nucleotides sequences showed that the isolates identified in this study are more closely related to Egyptian velogenic NDV isolates in class II, genotype VII of NDV with $97.00 \%$ to $99.3 \%$ identity. Tested isolates are also closely related to velogenic NDV isolates in class II, genotype VII NDVs from China, South Korea, Indonesia, and Peru to go with 95.4 to $83.2 \%$ identities. While standard LaSota NDV was more closely related to lentogenic NDV strains in class II, genotype II NDV obtained from GenBank with 100\% identity. These results were in harmony with [40],[41],[42] who identified velogenic NDV strains which belonged to class II genotype VII NDV. Also [43] identified NDV isolates that were closely related to other Egyptian isolates with 98\% identity and their isolates were related to other NDV strains from China, Korea and Israel with $94 \%$ identity

Analysis of deduced amino acid sequences of our isolates revealed that all deduced amino acid sequences were identical to amino acid sequences of velogenic strains of NDV in class II, genotype VII of NDV with exception of amino acid substitution at one site (K115E) in Mans2 isolate and amino acid substitution at one site (R71K) in Mans3 isolate which may be resulted from passaging in ECEs.

Deduced amino acid sequences of LaSota strain identified in this study was completely identicalto other lentogenic LaSota strains from Belgium (AJ629062) and Netherlands (AF077761). Class II, genotype II lentogenic LaSota strains has amino acid substitution at 12 sites when they compared with velogenic NDVs in class II, genotype VII of NDVs. Although the molecular basis of NDV virulence relies on multiple genes, the amino acid sequence motif at the cleavage site of the precursor F0 glycoprotein is the critical site for major changes in virus virulence. FO precursor glycoprotein of NDV cleaved into F1 and F2 during virus replication, this cleavage can be affected by protease that present in wide range of host tissue and organs recognizing a single arginine, trypsine like enzymes [44]. In this study the deduced amino acid sequences of the $F$ protein cleavage site of selected isolates and other velogenic Egyptian isolates in class II, genotype VII had multiple basic amino acids $\left({ }^{112} \mathrm{R}-\mathrm{R}-\right.$ $\mathrm{Q}-\mathrm{K}-\mathrm{R}^{\downarrow} \mathrm{F}^{117}$ ) which are characteristic of velogenic NDVs with K115Eamino acid substitution in Mans2isolate but LaSota strains (genotype II) has the amino acid sequence ${ }^{112} \mathrm{G}-\mathrm{R}-\mathrm{Q}-\mathrm{G}-$ $R^{\downarrow} L^{117}$ which is characteristic of lentogenic NDVs. These results were in agreement with [15] who reported that the amino acid sequence of the $F$ gene cleavage site determines the NDV virulence as many studies confirmed that the cleavage site present in virulent viruses has multiple basic amino acid residues at least three arginine or lysine between residues 113 and 116 at the $C$-terminus of the $F 2$ protein and Phenylalanine at residue 117 , which is the $\mathrm{N}$ terminus of the F1 protein. On the other hand, lentogenic strains are considered to be those with monobasic $F$ cleavage site $\left({ }^{112} \mathrm{G} / \mathrm{E}-\mathrm{K} / \mathrm{R}-\mathrm{Q}-\mathrm{G} / \mathrm{E}-\mathrm{R}^{116}\right)$ and a Leucine residue at position 117.In another study [45] it was concluded that the velogenic NDV strains contain a polybasic $F$ protein cleavage site with a consensus sequence of ${ }^{112}(R / K)-R-Q-(R / K) R^{\downarrow} F^{117}$ of high virulent NDV which can be recognized by ubiquitous host proteases (furin like protease) and thus making it possible to spread systemically and produce fatal infection.

\section{Conclusion}

Sequencing and phylogenetic analysis of $362 \mathrm{bp} \mathrm{F}$ gene fragment can detect the genotype of NDV. RT-PCR amplification 254bp NDV F gene fragmentsis and deduced amino acid sequence can differentiate between virulent and low virulent NDVs.

\section{Conflict of interest statement}


The authors have no conflict of interest

\section{Animal ethics committee permission}

The current research work was applied after standards of Research Ethics Committee, Faculty of Veterinary Medicine, Mansoura University.

\section{Authors' contributions}

Marwa Awad conducted the diagnostic steps and wrote the manuscript; Samah Moasd conducted phylogenetic analysis and helped in writing the manuscript; Ali El-Kenawy revised and edited the manuscript.

\section{REFERENCES}

1. Phale S. Newcastle Disease Virus: Structural and Molecular Basis of Pathogenicity. Med Chem. 2018;08.

2. Halasz F. Contributions to the knowledge of fowlpest (Veterinary Doctoral Dissertation). Budapest, Hungary: Communications of the Hungarian Royal Veterinary School, Patria. 1912;136.

3. Daubney R, Mansy W. The Occurrence of Newcastle Disease in Egypt. J Comp Pathol Ther. 1948;58:189-200.

4. El-Nassary BB, Eskarous JK. The distribution of fowl plague and newcastle disease in Upper Egypt. Arch Mikrobiol. 1960;36:147-50.

5. Amer MM, Ahmed HM, Elbayoumi KM, Kutkat MA. Pathogenicity of local identified NDV strain related to genotype VII to 28 day old commercial broiler chickens. MOJ Bioequivalence Bioavailability. 2018;5:227-30.

6. Ahmed AAS, Sabban MS, Ibrahim AMM, Amin A, Khafagi AR, Sheble A. Some Properties of Newcastle Disease Virus Isolates Recovered from Migratory Birds to Egypt. Zentralbl für Veterinärmedizin Reihe B. 2010;27:313-9.

7. International Committee on Taxonomy of Viruses(ICTV). http://ictvglobal/virusTaxonomyasp. 2018

8. Bello MB, Yusoff KM, Ideris A, Hair-Bejo M, Peeters BPH, Jibril AH, et al. Genotype Diversity of Newcastle Disease Virus in Nigeria: Disease Control Challenges and Future Outlook. Adv Virol. 2018;2018:1-17.

9. Alexander DJ. Newcastle Disease : Methods of Spread. In: Alexander D.J. (eds) Newcastle Disease. Developments in Veterinary Virology, vol 8. Springer, Boston, MA. 1988:256-72.

10. Li J, Meng C, Ren T, Wang W, Zhang Y, Yuan W, et al. Production, characterization, and epitope mapping of a monoclonal antibody against genotype VII Newcastle disease virus V protein. J Virol Methods. 2018;260:88-97.

11. OIE. Newcastle disease. OIE manual of standards for diagnostic tests and vaccines. Chapter 2.3.14 Version adopted by the World Assembly of Delegates of the OIE in May 2012. http://wwwoieint/fileadmin/Home/eng/Health_standards/tahm/2031 4_NEWCA STLE_DISpdf. 2012.

12. Goebel SJ, Taylor J, Barr BC, Kiehn TE, Castro-Malaspina HR, Hedvat CV, et al. Isolation of Avian Paramyxovirus 1 from a Patient with a Lethal Case of Pneumonia. J Virol. 2007;81:12709-14.

13. OIE. Manual of Diagnostic Tests and Vaccines for Terrestrial Animals. 2017.

14. Alexander DJ, Senne DA. Newcastle Disease and Other Avian Paramyxoviruses. In: A Laboratory Manual for the Isolation, Identification and Characterization of Avian Pathogens, Dufour-Zavala L. (Editor in Chief) Swayne D.E., Glisson J.R., Jackwood M.W., Pearson J.E., Reed W.M, Woolcock P.R., 4th ed., American Association of Avian Pathologists, Athens, GA. 2008:135-41.

15. Wood J, Laurie K, Engelhardt O. A Comparative Examination of Influenza Haemagglutination-Inhibition Assay Protocols - Development of a Consensus HI Protocol. (4th International Meeting) consise. September 2013.

16. Beguas R, Umali D. Genetic characterization of Newcastle Disease virus from broiler flocks in selected areas in Central Luzon, Philippines. Philippine Journal of Veterinary Medicine. June 2018;55.
17. Grimes SE. A basic laboratory manual for the small-scale production and testing of I-2 Newcastle disease vaccine. RAP publ. 2002;136.

18. Ali HH. Study of serologic status of Newcastle disease in broiler chickens by hemagglutination inhibition test in Suliamania Province. Glob J BioSci Biotechnol. 2015;4:364-9.

19. Pansota FM, Rizvi F, Sharif A, Javed MT, Muhammad G, Khan A, et al. Use of hyperimmune serum for passive immunization of chicks experimentally infected with Newcastle disease virus. Pak J Agri Sci. 2013;50:279-88.

20. Hemida MG. Identification and molecular characterization of velogenic neurotropic newcastle disease virus affecting chickens in eastern region of saudi arabia. Benha Vet Med J. December 2013;25:33-45.

21. Turner SP, Hartley CE, Buchan A, Skinner GRB. Preparation and efficacy of an inactivated subunit vaccine against Aujeszky's disease virus infection. Research in Veterinary Science. 1981;31:261-3.

22. Vögtlin A, Bruckner L, Ottiger H-P. Use of polymerase chain reaction (PCR) for the detection of vaccine contamination by infectious laryngotracheitis virus. Vaccine. 1999;17:2501-6.

23. Kant A, Koch G, Van Roozelaar DJ, Balk F, Huurne AT. Differentiation of virulent and non-virulent strains of Newcastle disease virus within 24 hours by polymerase chain reaction. Avian Pathol. 1997;26:837-49.

24. Hall TA. BioEdit: a user-friendly biological sequence alignment editor and analysis program for Windows 95/98/NT. Nucl Acids Symp Ser. 1999;41:95-8.

25. Abdel-Moneim AS, El-Sawah AA, Kandil MA. Characterization of Variant Strain of Newcastle Disease Virus in Egypt. J Vet Med Res. 2006;16:12 7.

26. Nabila O, Sultan S, Ahmed Al, Ibrahim RS, Sabra M. Isolation and pathotyping of Newcastle disease viruses from field outbreaks among chickens in the southern part of Egypt 2011-2012. Global Vet. 2014;12:237-43.

27. Abd El Aziz M, Abd El-Hamid H, Ellkany H, Nasef S, Nasr S, El Bestawy A. Biological and Molecular Characterization of Newcastle Disease Virus Circulating in Chicken Flocks, Egypt, During 2014-2015. Zagazig Vet J. 2016;44:9-20.

28. Abdel-Glil MY, Mor SK, Sharafeldin TA, Porter RE, Goyal SM. Detection and Characterization of Newcastle Disease Virus in Formalin-Fixed, Paraffin-Embedded Tissues from Commercial Broilers in Egypt. Avian Dis. 2014;58:118-23.

29. Balachandran $P$, Srinivasan $P$, Sivaseelan $S$, Balasubramaniam GA, Gopala Krishna Murthy TR. Isolation and characterization of Newcastle disease virus from vaccinated commercial layer chicken. Vet World. 2014;7:457-62.

30. Okwor EC, Eze DC. Newcastle disease in layers: Preliminary studies on the stress associated with onset of lay and initiation of clinical disease. African Journal of Microbiology Research. 2013;7:960-5.

31. McFerran JB, McCracken RM. Newcastle Disease. In: Alexander D.J. (eds) Newcastle Disease. Developments in Veterinary Virology, vol 8. Springer, Boston, MA. 1988:161-83. 54.

32. Kim SJ, Spradbrow PB, Mackenzie M. The isolation of lentogenic strains of newcastle disease virus in australia. Austral Vet J. 1978;54:183-7.

33. Bhadouriya S. Isolation and Characterization of the Newcastle Disease Virus (NDV) of Haryana Region Based on F-gene Sequence. J Anim Res. $2018 ; 8$.

34. Prama Rangga. Isolation Of Virulent Newcastle Disease Virusfile:///G:/New\%20folder/Rangga\%202013.htm. Friday, January 18, 2013.

35. ElShazly M, Ahmed B, ElSanousi A, Youssef Y. Isolation and Molecular Characterization of Newcastle Disease Virus Genotype VI from Pigeons in Egypt. Alexandria J Vet Sci. 2016;50:149-514

36. Miller PJ, Torchetti MK. Newcastle Disease Virus Detection and Differentiation from Avian Influenza. Methods Mol Biol. 2014;1161:2359.

37. Roy $P$, Venugopalan AT. Agar-gel-immunodiffusion and counterimmunoelectrophoresis for diagnosis of newcastle disease. Tropical Animal Health and Production. 1997;29:231-4.

38. Haider SA, Lapen RF, Kenzy SG. Use of Feathers in a Gel Precipitation Test for Marek's Disease. Poult Sci. 1970;49:1654-7.

39. Khan TA, Rue CA, Rehmani SF, Ahmed A, Wasilenko JL, Miller PJ, et al. Phylogenetic and Biological Characterization of Newcastle Disease Virus Isolates from Pakistan. J Clin Microbiol. 2010;48:1892-4. 
40. Liu XF, Wan HQ, Ni XX, Wu YT, Liu WB. Pathotypical and genotypical characterization of strains of Newcastle disease virus isolated from outbreaks in chicken and goose flocks in some regions of China during 1985-2001. Arch Virol. 2003;148:1387-403.

41. Rui $Z$, Juan $P$, Jingliang $S$, Jixun $Z$, Xiaoting $W$, Shouping $Z$, et al. Phylogenetic characterization of Newcastle disease virus isolated in the mainland of China during 2001-2009. Veterinary Microbiology. 2010;141:246-57.

42. Selim KM, Selim A, Arafa A, Hussein HA, Elsanousi AA. Molecular characterization of full fusion protein $(F)$ of Newcastle disease virus genotype VIId isolated from Egypt during 2012-2016. Veterinary World. 2018;11:930-8.

43. Wise MG, Suarez DL, Seal BS, Pedersen JC, Senne DA, King DJ, et al. Development of a Real-Time Reverse-Transcription PCR for Detection of Newcastle Disease Virus RNA in Clinical Samples. Journal of Clinical Microbiology. 2004;42:329-38.

44. Panda A, Huang Z, Elankumaran S, Rockemann DD, Samal SK. Role of fusion protein cleavage site in the virulence of Newcastle disease virus. Microb Pathogen. 2004;36:1-10.

45. de Leeuw OS, Hartog L, Koch G, Peeters BPH. Effect of fusion protein cleavage site mutations on virulence of Newcastle disease virus: nonvirulent cleavage site mutants revert to virulence after one passage in chicken brain. J Gener Virol. 2003;84:475-84. 